\title{
REVISÃO DE LITERATURA COM FOCO EM HISTÓRIA E FILOSOFIA DA CIÊNCIA: A CONTRIBUIÇÃO DO CADERNO BRASILEIRO DE ENSINO DE FÍSICA ENTRE $2010 \mathrm{E} 2020$
}

\author{
REVIEW OF THE LITERATURE FOCUSING ON HISTORY AND PHILOSOPHY OF \\ SCIENCE: THE CONTRIBUTION OF THE "CADERNO BRASILEIRO DE ENSINO \\ DE FÍSICA” FROM 2010 TO 2020
}

\author{
Wellington Lima da Silva ${ }^{1}$ \\ Wanderley Vitorino da Silva Filho ${ }^{2}$ \\ Igor Tavares Padilha ${ }^{3}$
}

RESUMO: O presente trabalho busca fazer um levantamento do estado da arte da abordagem História e Filosofia das Ciências (HFC) em sala de aula em um dos periódicos mais tradicionais na área de Ensino de Física: o Caderno Brasileiro de Ensino de Física (CBEF) da Universidade Federal de Santa Catarina (UFSC), e a partir de tal fazer uma análise do material selecionado entre os anos de 2010 - 2020. Os resultados relatados nos trabalhos apontam que o uso da HFC possibilita discussões sobre o processo de construção do conhecimento científico, promovendo um estudo contextualizado e aproximando o aluno do processo evolutivo da ciência. Foi verificado que há uma carência de trabalhos que abordam a HFC em sala de aula julgando pelo número de publicações no período analisado. Espera-se que a análise desse levantamento sirva de auxílio para profissionais e discentes de Física que tenham interesse na abordagem HFC em sala de aula, onde os quais possam refletir sobre as intervenções didáticas realizadas nos trabalhos selecionados.

Palavras-chave: História e filosofia da ciência. Ensino de física. Revisão de literatura.

ABSTRACT: The present paper presents a survey of the state of art of the approach given by History and Philosophy of Sciences (HPS) as applied to the classroom, registered in one of the most traditional Brazilian journals on Physics Teaching: the "Caderno Brasileiro de Ensino de Física" (CBEF), from the Federal University of Santa

'Graduando do Curso de Licenciatura Plena em Física da Universidade Federal do Amazonas (UFAM). Bolsista do Programa de Educação Tutorial (PET Física) e Membro do Grupo de Pesquisa ECIMATH Estação Ciências, Matemática, Astronomia, Tecnologia e História das Ciências da Universidade Federal do Amazonas (UFAM). https://orcid.org/oooo-ooo2-5639-16o8. E-mail: wellingtonlnilo@gmail.com

${ }^{2}$ Doutor em Ensino, Filosofia e História das Ciências pela Universidade Federal da Bahia (UFBA). Professor Adjunto do Departamento de Física e Líder do Grupo de Pesquisa ECIMATH - Estação Ciências, Matemática, Astronomia, Tecnologia e História das Ciências da Universidade Federal do Amazonas (UFAM).https://orcid.org/oooo-ooo2-1591-3668. E-mail: vitorino@ufam.edu.br

3 Doutor em Física pela Universidade Federal Fluminense (UFF). Professor Associado I do Departamento de Física e Tutor do Programa de Educação Tutorial (PET Física) da Universidade Federal do Amazonas (UFAM). https://orcid.org/oooo-ooo2-3949-1244. E-mail: igorfis@ufam.edu.br. 
Catarina. From this source we have analyzed selected material from 2010 to 2020. The results presented in these papers indicate that the application of HPS allows discussion of the process of construction of scientific knowledge, promoting a contextualized study and approximating the student to the evolutionary process of science. One also verified that there is a lack of studies on HPS approaches in the classroom, considering the published papers during the period analyzed. One hopes that the analysis of the revision may contribute to physics professionals and students who are interested in the application of HPS in the classroom, allowing one to reflect on the didactical interventions presented in the selected papers.

Keywords: History and Philosophy of Science. Physics Teaching. Review of Literature.

\section{INTRODUÇÃO}

No cenário atual do ensino de Física, ainda predomina o método tradicional de aulas expositivas focadas na resolução de exercícios algébricos e memorização de conceitos e leis. Várias abordagens de ensino na área de Física são utilizadas, das quais podemos citar: a experimentação; o uso das Tecnologias da Informação e Comunicação (TICs); Ciência, Tecnologia e Sociedade (CTS); História e Filosofia da Ciência (HFC); e a leitura de diferentes gêneros textuais acerca dos assuntos de Física.

De acordo com Martins (2007), o termo 'História e Filosofia da Ciência' - HFC é utilizado pelos pesquisadores da área da Didática das Ciências para referir um campo do conhecimento composto por um conjunto de saberes até certo ponto interrelacionado e coeso. Este autor utiliza uma frase de Lakatos (1978, p.21): “A Filosofia da Ciência sem História da Ciência é vazia; a História da Ciência sem Filosofia da Ciência é cega"como representante desta definição.

Existem tarefas urgentes que precisam ser enfrentadas para que o ensino da
Física possa ser melhorado. Entre elas, e ao nosso alcance, está a necessidade
de se recuperar a noção de que a Física é um processo onde o confronto de
ideias está sempre presente. É nesse sentido que o estudo da história da Física
e da sua epistemologia são mais do que presentes; no estudo combinado dessas
duas disciplinas repousa a possibilidade de se compreender o processo de
construção do conhecimento. (Robilotta, 1988 , p. 17 ).

As justificativas para a abordagem de elementos históricos da Física no ensino dessa disciplina vêm se avolumando. Entre elas, destacamos as de que a adoção de uma abordagem histórica poderia contribuir para: a compreensão dos processos da ciência e 
sua natureza; a aprendizagem significativa dos conceitos e das equações; a problematização das concepções alternativas dos estudantes; a incrementação da cultura geral; a desmitificação do método científico; o desencadeamento do interesse pelo estudo da Física; o entendimento das inter-relações entre ciência, tecnologia e sociedade; a humanização das ciências, aproximando-as dos interesses da comunidade; o aumento da reflexão crítica durante as aulas; o entendimento da epistemologia da ciência; e a compreensão das controvérsias, dos equívocos e dos dilemas inerentes ao desenvolvimento científico (Pessoa Junior, 1996; Peduzzi, 20or; Bassalo, 1992; Matthews, 1995; Silva, 2010; Robilotta, 1988).

Conforme Matthews (1995), a História, Filosofia e Sociologia da Ciência não é a solução para o problema da educação, mas são medidas auxiliares que podem ajudar a avançar nessa mudança, como: humanizar as ciências e assim tentar aproximar aos interesses da comunidade; transformar as aulas em algo que seja reflexivo e desafiador, permitindo a formação do pensamento crítico; colaborar para um entendimento de forma efetiva dos conteúdos científicos; demonstrar que a Ciência é mutável, instável e passa por um processo evolutivo; aprimorar a formação de professores ao passo que compreendem a estrutura de sua ciência.

Apesar das discussões e pesquisas no Brasil sobre a introdução da HFC serem relativamente recentes, no exterior essa inserção já era discutida e fomentada há décadas por especialistas e instituições. Um exemplo notável foi o projeto educacional desenvolvido pela National Science Foundation com a Universidade de Harvard e implementado nos EUA entre os anos de 1962 e 1970, cujo nome original é Project Physics Course. Este se destinava ao ensino básico, mas acabou ganhando a adesão em universidades nas disciplinas introdutórias de cursos de ciência, o mesmo era fundamentado em princípios históricos, componente humanístico e preocupado com as dimensões culturais e filosóficas da ciência, e desenvolvido a partir da colaboração de historiadores e filósofos da ciência, físicos, astrônomos, químicos, educadores de ciências, psicólogos, especialistas de avaliação, dentre outros profissionais (SAUERWEIN; DELIZOICOV, 2008). 
Um reflexo do consenso quanto à inserção da HFC no ensino são as orientações expressas nos principais documentos que norteiam a educação nacional. Para o intervalo entre 2010 e 2020, vamos considerar dois deles: os Parâmetros Curriculares Nacionais (PCN's) e a Base Nacional Comum Curricular (BNCC), ambos recomendam a inserção de conteúdos de natureza histórico-filosófica.

Nos PCN's para o Ensino Médio pode-se observar essas recomendações no tópico Conhecimentos em Física no documento Parte III - Ciências da Natureza e suas Tecnologias, onde se menciona: Compreender a construção do conhecimento físico como um processo histórico, em estreita relação com as condições sociais, políticas e econômicas de uma determinada época. [...] Compreender a Física como parte integrante da cultura contemporânea, identificando sua presença em diferentes âmbitos e setores [...]. Reconhecer, em situações concretas, a relação entre Física e ética, seja na definição de procedimentos para a melhoria das condições de vida, seja em questões como do desarmamento nuclear ou em mobilizações pela paz mundial (BRASIL,1999).

Já a BNCC para o Ensino Médio - Ciências da Natureza e suas Tecnologias, cita:

A contextualização social, histórica e cultural da ciência e a tecnologia é fundamental para que elas sejam compreendidas como empreendimentos humanos e sociais. Na BNCC, portanto, propõe-se também discutir o papel do conhecimento científico e tecnológico na organização social, nas questões ambientais, na saúde humana e na formação cultural, ou seja, analisar as relações entre ciência, tecnologia, sociedade e ambiente. [...] Ainda com relação à contextualização histórica, propõe-se, por exemplo, a comparação de distintas explicações científicas propostas em diferentes épocas e culturas e o reconhecimento dos limites explicativos das ciências, criando oportunidades para que os estudantes compreendam a dinâmica da construção do conhecimento científico. (BRASIL, 20I8).

Já a escolha do intervalo de tempo entre 2010 e 2020 deu-se tendo em vista a obtenção de um retrato atual da HFC em sala de aula na perspectiva de ilustrar a transição de dois documentos que norteiam a educação nacional durante esse período: dos PCN's para a BNCC. Esta última obrigatória em todos os currículos de todas as redes de ensino do país, públicas e particulares, ao contrário dos PCN's, que devem continuar existindo, mas apenas como documentos orientadores não obrigatórios.

Pretende-se com esse trabalho apresentar um levantamento dos artigos publicados no período de 2010 a 2020 disponíveis no Caderno Brasileiro de Ensino de Física (CBEF) da Universidade Federal de Santa Catarina (UFSC) que abordem a HFC 
em sala de aula de Física. Objetiva-se ainda expor a análise de uma amostra destes artigos traçando uma visão geral de como o tema é trabalhado pela comunidade de professores e pesquisadores no Ensino de Física, como ele está inserido no ensino, quais as problemáticas em torno da sua inserção, limitações e melhorias apontadas no ensino a partir da abordagem aqui tratada. Este levantamento poderá auxiliar na verificação das principais tendências e assuntos que têm sido contemplados em propostas para aulas de Física, possibilitando uma reflexão sobre as pesquisas que visam à inserção do tema no Ensino.

\section{METODOLOGIA}

Ao realizarmos análises de trabalhos anteriormente publicados, evidenciamos a evolução da temática ao longo de um determinado período, contribuindo assim, na divulgação e apropriação do tema estudado. Dessa maneira, esse trabalho se constituiu como sendo um trabalho de "Revisão de Literatura" (FIGUEREDO, 1990). As revisões preenchem dois papéis interligados: I - constituem-se em parte integral do desenvolvimento da ciência (função histórica) e 2 - fornecem aos profissionais de qualquer área, informação sobre o desenvolvimento corrente da ciência e sua literatura (função de atualização).

Dessa forma, foi utilizada a revisão sistemática de literatura que, atualmente, tem sido considerada uma das maneiras mais atrativas e eficazes de caracterizar sinteticamente e extrair juízos confiáveis sobre o grande conjunto da literatura especializada de uma determinada área de pesquisa. Em contraste com as tradicionais formas de revisão narrativa, uma revisão sistemática permite obter, de forma crítica e sintetizada, informações relevantes sobre os principais resultados da área de pesquisa, o que pode ser de grande utilidade para os pesquisadores (BENNETT et al., 2005; DIOS et al., 2007).

O levantamento dos artigos para análise foi feito por meio de busca direta, no intervalo entre os anos de 2010 e 2020, no site de um dos periódicos brasileiros mais tradicionais na área de ensino de Física: o Caderno Brasileiro de Ensino de Física 
(CBEF), periódico em formato digital da Universidade Federal de Santa Catarina (UFSC). O Caderno Brasileiro de Ensino de Física (CBEF) é uma publicação do Departamento de Física da UFSC, desde dezembro de 1984. É um periódico quadrimestral, arbitrado, indexado, direcionado prioritariamente para os cursos de Licenciatura em Física e amplamente utilizado em pós-graduações em Ensino de Ciências/Física e em cursos de aperfeiçoamento para professores do Nível Médio. Os artigos geralmente encontram-se em português, porém conta com algumas publicações em espanhol $\mathrm{e}$ inglês.

Essa busca de artigos foi feita de forma minuciosa, número por número no intervalo citado, selecionando os artigos já pertencentes à categoria $\mathrm{HFC}$ e depois filtrando pela leitura do título, resumo e palavras-chave porque alguns, mesmo não estando categorizados se encaixam em tal. Para o ano de 2010 , quando não havia a categoria HFC, foram utilizados os critérios acima. Foram selecionados 91 artigos que estavam relacionados à temática geral de HFC. Logo após essa seleção, foi feita uma triagem para selecionar os artigos referentes ao uso didático de HFC como metodologia e resultados em sala de aula, dos quais desses 91 foram selecionados apenas 13 artigos. No geral, os outros 78 tratam de propostas didáticas de natureza teórica, sem intervenção didática em sala de aula.

\section{HISTÓRIA E FILOSOFIA DA CIÊNCIA NO ENSINO}

A História e Filosofia da Ciência (HFC) é considerada uma área de conhecimento que pode trazer contribuições ao ensino/aprendizagem de Ciências. Podemos dizer que a abordagem HFC funciona como uma estratégia didática facilitadora na compreensão de conceitos, leis, modelos e teorias científicas. Estudos apontam que essa abordagem pode contribuir para a formação de uma cultura científica, levando os alunos a assumirem uma postura crítica, aspecto evidenciado nos documentos oficiais. Em relação à abordagem HFC, Saito (2010, p.4) ressalta que embora, "seja uma mediadora para a aprendizagem de Ciências, não é método de 
ensino, mas uma provedora de recursos que conduz à reflexão sobre o processo de construção do conhecimento científico.

A introdução de alguns tópicos de HFC no ensino pode possibilitar aos educadores "levar seus alunos a perceber que os conhecimentos científicos não estão distanciados das necessidades da sociedade e da época no qual foram elaborados, sofrendo suas influências e, por sua vez, influenciando-as” (TRINDADE et al., 2oro, p.120). Tais benefícios não são notados em um ensino considerado tradicional em que o conhecimento científico é enfatizado enquanto produto final, em detrimento do processo percorrido durante o seu desenvolvimento. Sobre isso, Neves (1998, p.75) salienta que "alijar a ciência de seu processo histórico, de suas contingências e de suas representações, é condená-la a um destino que se assemelha mais à religião, ligando paradigmas a dogmas, e sociedades científicas a seitas”.

A abordagem HFC não deve ser interpretada como um substituto ao ensino de conteúdos científicos, mas como uma estratégia facilitadora de seu aprendizado de modo que o resultado final do processo supere a simples assimilação de conteúdos.

Abordar um conteúdo escolar de Física por meio do recurso à HFC, por exemplo, não implica na substituição de aulas de Física por aulas de História ou Filosofia. Tal compreensão é de suma importância para os professores dispostos a basear seus trabalhos numa abordagem HFC, de modo que esta contribua de fato ao ensino de Ciências.

O mau uso da abordagem HFC pode representar um entrave ao ensino de Ciências. Martins (2006) cita como exemplos de uso inadequado da História e Filosofia da Ciência: a redução da História da Ciência a nomes, datas e anedotas; as concepções errôneas sobre o método científico e o uso de argumentos de autoridade. Bastos (1998) por sua vez destaca os problemas decorrentes pelo seu mau uso. Para este autor, além de incorrer em erros factuais grosseiros, o mau uso da abordagem HFC ignora as relações entre o processo de produção do conhecimento científico e o contexto externo (social, político, econômico e cultural). O mau uso pode ainda estimular a ideia de que os atuais conhecimentos científicos seriam verdades imutáveis ao glorificar o presente e seus 
paradigmas, menosprezando a importância das correntes científicas divergentes das atuais, a riqueza dos debates ocorridos no passado, as descontinuidades entre passado $e$ presente, etc. $\mathrm{O}$ mau uso também pode propagar a visão de que os conhecimentos produzidos pelas ciências progrediram apenas por meio de descobertas fabulosas realizadas por cientistas geniais que aparecem em determinados períodos de tempo.

\section{ANÁLISE DOS DADOS}

$\mathrm{Na}$ tabela I, podemos ver a quantidade de artigos relacionados à temática geral de HFC comparado à quantidade de artigos que trata da intervenção didática em sala de aula por meio da HFC no período entre 2010 e 2020.

Tabela I - Vista Geral da HFC (CBEF 2010 - 2020)

\begin{tabular}{|c|c|c|}
\hline Ano/Volume & $\begin{array}{c}\text { Número de Artigos de HFC } \\
\text { (Propostas Didáticas e } \\
\text { Teoria) }\end{array}$ & $\begin{array}{c}\text { Número de Artigos de } \\
\text { HFC (Sala de Aula) }\end{array}$ \\
\hline $2010 / 27$ & 6 & I \\
\hline $2011 / 28$ & 8 & I \\
\hline $2012 / 29$ & 6 & I \\
\hline $2013 / 30$ & 4 & o \\
\hline $2014 / 31$ & 5 & o \\
\hline $2015 / 32$ & II & 2 \\
\hline $2016 / 33$ & 9 & 2 \\
\hline $2017 / 34$ & II & 2 \\
\hline $2018 / 35$ & IO & 2 \\
\hline $2019 / 36$ & IO & I \\
\hline $2020 / 37$ & I4 & I \\
\hline Total & 9I & 13 \\
\hline
\end{tabular}

Fonte: Elaborada pelos autores (2021) 
A maioria (aproximadamente $85,71 \%$ ) dos trabalhos que norteiam a HFC trata de propostas didáticas sem intervenção em sala de aula e de tópicos de natureza teórica, enquanto apenas $14,29 \%$ tratam da HFC em sala, onde se pode ver e analisar os resultados de sua aplicação prática. Um número baixo, considerando todas as publicações que norteiam essa abordagem nesse intervalo de tempo. Esse dado é preocupante já que se apresenta no CBEF os benefícios da inserção da HFC no ensino (em todos os níveis) e poucos dados práticos se tem para fazer qualquer análise da efetividade dessa abordagem no ensino de Física. Levando-se em consideração os i3 artigos que tratam da intervenção didática da HFC em sala de aula, podemos mostrar os assuntos abordados nos mesmos e em quais categorias do CBEF se encontram. Os anos de 2013 e 2014 não tiveram artigos que tratassem dessa abordagem em sala de aula. Foram usados indicadores para citar os artigos no corpo do texto, como se pode ver na tabela abaixo e onde localizá-los no CBEF:

Tabela 2 - Dados Gerais da HFC em Sala de Aula (CBEF 2010 - 2020)

\begin{tabular}{|c|c|c|c|c|c|c|}
\hline Ano/Volume & Indicador & $\begin{array}{c}\text { Título do } \\
\text { Artigo }\end{array}$ & Autor(es) & Categoria & № & Tema \\
\hline $2010 / 27$ & Aor & $\begin{array}{l}\text { O Teatro como } \\
\text { Ferramenta de } \\
\text { Aprendizagem } \\
\text { da Física de } \\
\text { Problematização } \\
\text { da Natureza da } \\
\text { Ciência }\end{array}$ & $\begin{array}{c}\text { MEDINA, M.; } \\
\text { BRAGA, M. }\end{array}$ & Artigos & 2 & $\begin{array}{l}\text { Ensino de Física / } \\
\text { História da Física }\end{array}$ \\
\hline $2011 / 28$ & $\mathrm{Ao2}$ & $\begin{array}{c}\text { História da } \\
\text { Ciência e Uso } \\
\text { da } \\
\text { Instrumentação: } \\
\text { Construção de } \\
\text { um } \\
\text { Transmissor de } \\
\text { Voz como } \\
\text { Estratégia de } \\
\text { Ensino }\end{array}$ & $\begin{array}{l}\text { RINALDI, E.; } \\
\text { GUERRA, A. }\end{array}$ & $\begin{array}{c}\text { Relatos e } \\
\text { Propostas de } \\
\text { Experiências } \\
\text { Didáticas }\end{array}$ & 3 & $\begin{array}{c} \\
\text { História e } \\
\text { Filosofia da } \\
\text { Ciência / Ensino } \\
\text { de Física / } \\
\text { Eletromagnetismo }\end{array}$ \\
\hline
\end{tabular}




\begin{tabular}{|c|c|c|c|c|c|c|}
\hline $2012 / 29$ & $\mathrm{Ao}_{3}$ & $\begin{array}{c}\text { O Projeto } \\
\text { Erastótenes: A } \\
\text { Reprodução de } \\
\text { um } \\
\text { Experimento } \\
\text { Histórico como } \\
\text { Recurso para a } \\
\text { Inserção de } \\
\text { Conceitos da } \\
\text { Astronomia no } \\
\text { Ensino Médio }\end{array}$ & $\begin{array}{l}\text { SANTOS, A. J. } \\
\text { J; VOELZKE, } \\
\text { M. R; } \\
\text { ARAÚJO, M. } \\
\text { S. T. }\end{array}$ & $\begin{array}{c}\text { História e } \\
\text { Filosofia da } \\
\text { Ciência }\end{array}$ & 3 & $\begin{array}{l}\text { História da } \\
\text { Ciência / } \\
\text { Astronomia }\end{array}$ \\
\hline \multirow[b]{2}{*}{$2015 / 32$} & Ao4 & $\begin{array}{l}\text { A Origem do } \\
\text { Universo como } \\
\text { Tema para } \\
\text { discutir a } \\
\text { Natureza da } \\
\text { Ciência no } \\
\text { Ensino Médio }\end{array}$ & $\begin{array}{c}\text { GUTTMANN, } \\
\text { G. A. M.; } \\
\text { BRAGA, M. }\end{array}$ & $\begin{array}{c}\text { História e } \\
\text { Filosofia da } \\
\text { Ciência }\end{array}$ & 2 & $\begin{array}{l}\text { História da } \\
\text { Ciência / } \\
\text { Cosmologia }\end{array}$ \\
\hline & Aos & $\begin{array}{c}\text { O Estudo da } \\
\text { Espectroscopia } \\
\text { no Ensino } \\
\text { Médio através } \\
\text { uma } \\
\text { Abordagem } \\
\text { Histórico- } \\
\text { Filosófica: } \\
\text { Possibilidade de } \\
\text { Interseção entre } \\
\text { as Disciplinas } \\
\text { de Química e } \\
\text { Física }\end{array}$ & $\begin{array}{l}\text { SILVA, H. R. } \\
\text { A.; MORAES, } \\
\text { A. G. }\end{array}$ & $\begin{array}{c}\text { História e } \\
\text { Filosofia da } \\
\text { Ciência }\end{array}$ & 2 & $\begin{array}{c}\text { História da } \\
\text { Ciência / Ensino } \\
\text { de Física / Física } \\
\text { Moderna }\end{array}$ \\
\hline \multirow[t]{2}{*}{$2016 / 33$} & Ao6 & $\begin{array}{c}\text { Um Estudo de } \\
\text { Caso Histórico } \\
\text { sobre o } \\
\text { Experimento de } \\
\text { Foucault no } \\
\text { Brasil, } \\
\text { Elaborado por } \\
\text { uma Professora } \\
\text { do Ensino } \\
\text { Médio na } \\
\text { Formação } \\
\text { Continuada a } \\
\text { Distância }\end{array}$ & $\begin{array}{c}\text { JUNIOR, E. R.; } \\
\text { LUNA, F. J.; } \\
\text { HYGINO, C. } \\
\text { B.; } \\
\text { LINHARES, } \\
\text { M. P.; } \\
\text { BASEGODA, } \\
\text { M. R. C. F. A. }\end{array}$ & $\begin{array}{c}\text { Formação } \\
\text { Inicial e } \\
\text { Continuada } \\
\text { do Professor } \\
\text { de Física }\end{array}$ & I & $\begin{array}{c}\text { Formação de } \\
\text { Professores / } \\
\text { História da Física }\end{array}$ \\
\hline & $\mathrm{Ao} 7$ & $\begin{array}{c}\text { Os Conceitos de } \\
\text { Espaço e de } \\
\text { Tempo como } \\
\text { Protagonistas } \\
\text { no Ensino de } \\
\text { Física: Um } \\
\text { Relato de uma } \\
\text { Sequência }\end{array}$ & $\begin{array}{l}\text { REIS, U. V.; } \\
\text { REIS, J. C. }\end{array}$ & $\begin{array}{l}\text { Pesquisa em } \\
\text { Ensino de } \\
\text { Física }\end{array}$ & 3 & $\begin{array}{c}\text { História e } \\
\text { Filosofia da } \\
\text { Ciência / } \\
\text { Conceitos Básicos } \\
\text { de Física / } \\
\text { História da Física }\end{array}$ \\
\hline
\end{tabular}




\begin{tabular}{|c|c|c|c|c|c|c|}
\hline & & $\begin{array}{l}\text { Didática com } \\
\text { Abordagem } \\
\text { Histórico- } \\
\text { Filosófica }\end{array}$ & & & & \\
\hline \multirow[t]{2}{*}{$2017 / 34$} & Ao8 & $\begin{array}{c}\text { Concepções } \\
\text { sobre a } \\
\text { Natureza da } \\
\text { Ciência: A } \\
\text { Trajetória dos } \\
\text { Estudantes de } \\
\text { uma Disciplina } \\
\text { sobre Evolução } \\
\text { dos Conceitos } \\
\text { da Física }\end{array}$ & $\begin{array}{l}\text { PENA, F. L. A.; } \\
\text { TEIXEIRA, E. } \\
\text { S. }\end{array}$ & $\begin{array}{c}\text { Relatos e } \\
\text { Propostas de } \\
\text { Experiências } \\
\text { Didáticas }\end{array}$ & I & $\begin{array}{l}\text { Ensino de Física / } \\
\text { História da Física }\end{array}$ \\
\hline & Aog & $\begin{array}{c}\text { Laboratório } \\
\text { Desafiador e } \\
\text { História da } \\
\text { Ciência: Um } \\
\text { Relato de } \\
\text { Experiência } \\
\text { com o } \\
\text { Experimento de } \\
\text { Oersted }\end{array}$ & $\begin{array}{c}\text { PINTO, J. A. } \\
\text { F.; SILVA, A. } \\
\text { P. B; } \\
\text { FERREIRA, E. } \\
\text { J. B. }\end{array}$ & $\begin{array}{c}\text { Relatos e } \\
\text { Propostas de } \\
\text { Experiências } \\
\text { Didáticas }\end{array}$ & I & $\begin{array}{l}\text { História da Física } \\
\text { / Ensino de Física } \\
\text { Eletromagnetismo }\end{array}$ \\
\hline \multirow[b]{2}{*}{$2018 / 35$} & Aio & $\begin{array}{l}\text { O Maior Erro } \\
\text { de Einstein? } \\
\text { Debatendo o } \\
\text { Papel dos Erros } \\
\text { na Ciência } \\
\text { através de um } \\
\text { Jogo Didático } \\
\text { sobre } \\
\text { Cosmologia }\end{array}$ & $\begin{array}{l}\text { BAGDONAS, } \\
\text { A.; ZANETC, } \\
\text { J.; GURGEL, I. }\end{array}$ & $\begin{array}{l}\text { História e } \\
\text { Filosofia da } \\
\text { Ciência }\end{array}$ & I & $\begin{array}{c}\text { História da } \\
\text { Ciência / Ensino } \\
\text { de Física / } \\
\text { Cosmologia }\end{array}$ \\
\hline & AII & $\begin{array}{c}\text { História e } \\
\text { Filosofia da } \\
\text { Ciência na } \\
\text { Formação } \\
\text { Docente: } \\
\text { Trabalhando } \\
\text { com Animações } \\
\text { Digitais }\end{array}$ & $\begin{array}{c}\text { HIDALGO, J. } \\
\text { M.; } \\
\text { SCHIVANI, } \\
\text { M.; } \\
\text { MARTINS, M. } \\
\text { S. }\end{array}$ & $\begin{array}{l}\text { História e } \\
\text { Filosofia da } \\
\text { Ciência }\end{array}$ & 3 & $\begin{array}{c}\text { Formação de } \\
\text { Professores / } \\
\text { História da Física }\end{array}$ \\
\hline
\end{tabular}




\begin{tabular}{|c|c|c|c|c|c|c|}
\hline $2019 / 36$ & $\mathrm{~A}_{12}$ & $\begin{array}{l}\text { O Violão no } \\
\text { Ensino de } \\
\text { Acústica: Uma } \\
\text { Proposta com } \\
\text { Enfoque } \\
\text { Histórico- } \\
\text { Epistemológico } \\
\text { em uma } \\
\text { Unidade de } \\
\text { Ensino } \\
\text { Potencialmente } \\
\text { Significativa }\end{array}$ & $\begin{array}{l}\text { LIMA, D. O.; } \\
\text { DAMASIO, F. }\end{array}$ & $\begin{array}{c}\text { Relatos e } \\
\text { Propostas de } \\
\text { Experiências } \\
\text { Didáticas }\end{array}$ & 3 & $\begin{array}{c}\text { História da Física } \\
\text { / Ensino de Física } \\
\text { / Acústica }\end{array}$ \\
\hline $2020 / 37$ & $\mathrm{~A}_{13}$ & $\begin{array}{c}\text { Abordagem } \\
\text { Histórico- } \\
\text { Didática para o } \\
\text { Ensino da } \\
\text { Teoria } \\
\text { Eletrofraca } \\
\text { utilizando } \\
\text { Simulações } \\
\text { Computacionais } \\
\text { de } \\
\text { Experimentos } \\
\text { Históricos }\end{array}$ & $\begin{array}{l}\text { COSTA, M.; } \\
\text { LOURDES, I. }\end{array}$ & $\begin{array}{c}\text { Relatos e } \\
\text { Propostas de } \\
\text { Experiências } \\
\text { Didáticas }\end{array}$ & I & $\begin{array}{l}\text { História da Física } \\
\text { / Ensino de Física } \\
\text { / Física Moderna }\end{array}$ \\
\hline
\end{tabular}

Fonte: Elaborada pelos autores (2021)

As categorias que mais abarcaram artigos de $\mathrm{HFC}$ em sala de aula durante o intervalo de tempo entre 2010 e 2020 no CBEF foram a de "História e Filosofia da Ciência" e de "Relatos e Propostas de Experiências Didáticas" com aproximadamente $38,46 \%$ e total de 5 artigos contidos em cada. As demais categorias contaram com aproximadamente $7,69 \%$ e total de I artigo cada. Se tratando de aplicação de HFC em sala de aula, é plausível considerar que haja trabalhos em outras categorias, principalmente na de "Relatos e Propostas de Experiências Didáticas". O que nos leva a concluir que para fazer uma triagem sobre determinado assunto - aqui HFC em sala de aula - temos que considerar todas as categorias do periódico e não apenas a que concentra o título da pesquisa porque muitos artigos mesmo abarcando duas ou mais categorias, encontram-se apenas categorizado em uma delas.

Dos 13 artigos analisados, 5 deles (aproximadamente 38,46 \%) tratam da História da Física, 2 de Eletromagnetismo (aproximadamente 15,38 \%), 2 de Física Moderna (aproximadamente 15,38\%), 2 de Cosmologia (aproximadamente 15,38\%), I de Acústica 
(aproximadamente 7,69 \%) e I de Astronomia (aproximadamente 7,69 \%). Para essa seleção, foi levada em consideração a última palavra da coluna "Tema" da Tabela 2. Se tratando dos artigos que só possuem "História da Física" como classificação foi levado em consideração os conteúdos que norteiam tais, sendo que tratam especificamente de contextos históricos e não direcionam exatamente para uma área da Física em específico. Foram identificadas 2 abordagens na área de Física Moderna. Já na área de Física Básica (ensino médio e superior) foram identificadas 3 abordagens (Eletromagnetismo e Acústica). Não foram identificadas abordagens de HFC em sala de aula em outras áreas da Física como: Mecânica, Termologia, Hidrostática e Óptica, o que não significa que essas áreas não sejam abordadas em periódicos, apenas que no recorte temporal definido para a pesquisa no CBEF não foram identificados tais temas.

Outros dados gerais também podem ser extraídos dos 13 artigos selecionados, nos quais se encontram na tabela abaixo:

Tabela 3 - Outros Dados Gerais da HFC em Sala de Aula (CBEF 2010 - 2020)

\begin{tabular}{|c|c|c|c|c|c|}
\hline Ano/Volume & Indicador & $\begin{array}{l}\text { Publicação } \\
\text { (Por Estado) }\end{array}$ & $\begin{array}{l}\text { Público Alvo / } \\
\text { Nível de Ensino }\end{array}$ & $\begin{array}{c}\text { Participação } \\
\text { dos } \\
\text { Envolvidos }\end{array}$ & Espaço Físico \\
\hline $2010 / 27$ & Aor & $\mathrm{RJ}$ & $\begin{array}{l}\text { Ensino Regular - } \\
\text { Ensino Médio ( } \mathrm{I} \text { e e } \\
2^{-} \text {ano) }\end{array}$ & Voluntária & $\begin{array}{l}\text { Formal (sala de aula) } \\
\text { e não-formal (teatro) }\end{array}$ \\
\hline $2011 / 28$ & Ao2 & $\mathrm{MG} / \mathrm{RJ}$ & $\begin{array}{l}\text { Ensino Regular - } \\
\text { Ensino Médio (Io e } \\
\text { 2o ano) }\end{array}$ & Obrigatória & $\begin{array}{c}\text { Formal (sala de aula } \\
\text { e laboratório da } \\
\text { escola) }\end{array}$ \\
\hline $2012 / 29$ & Ao3 & SE/SP & $\begin{array}{c}\text { Ensino Regular e } \\
\text { Técnico - Médio (3o } \\
\text { ano) }\end{array}$ & Voluntária & $\begin{array}{c}\text { Formal e não-formal } \\
\text { (sala de aula, } \\
\text { laboratório de } \\
\text { informática e } \\
\text { dependências da } \\
\text { escola) }\end{array}$ \\
\hline $2015 / 32$ & Ao4 & $\mathrm{RJ}$ & $\begin{array}{l}\text { Ensino Regular - } \\
\text { Ensino Médio ( } 2^{-} \\
\text {ano })\end{array}$ & Voluntária & Formal (sala de aula) \\
\hline
\end{tabular}




\begin{tabular}{|c|c|c|c|c|c|}
\hline & Aos & $\mathrm{RJ}$ & $\begin{array}{l}\text { Ensino Regular - } \\
\text { Ensino Médio (3o } \\
\text { ano) }\end{array}$ & Voluntária & $\begin{array}{c}\text { Formal (sala de aula } \\
\text { e laboratório didático } \\
\text { da escola) }\end{array}$ \\
\hline \multirow{2}{*}{$2016 / 33$} & Ao6 & $\mathrm{ES} / \mathrm{RJ}$ & $\begin{array}{l}\text { Formação de } \\
\text { Professores - } \\
\text { Ensino Médio } \\
\quad \text { (Física) }\end{array}$ & Voluntária & $\begin{array}{c}\text { Não-formal (curso a } \\
\text { distância) }\end{array}$ \\
\hline & Ao7 & $\mathrm{RJ}$ & $\begin{array}{l}\text { Ensino Regular - } \\
\text { Ensino Médio ( } \mathrm{I} \text { o } \\
\text { ano) }\end{array}$ & Obrigatória & Formal (sala de aula) \\
\hline \multirow{2}{*}{$2017 / 34$} & Ao8 & BA & $\begin{array}{c}\text { Ensino Superior - } \\
\text { Bacharelado e } \\
\text { Licenciatura em } \\
\text { Física (finalistas) }\end{array}$ & Voluntária & Formal (sala de aula) \\
\hline & Aog & $\mathrm{PB}$ & $\begin{array}{l}\text { Ensino Regular - } \\
\text { Ensino Médio (3o } \\
\text { ano) }\end{array}$ & Obrigatória & $\begin{array}{c}\text { Formal (sala de aula } \\
\text { e laboratório da } \\
\text { escola) }\end{array}$ \\
\hline \multirow{2}{*}{$2018 / 35$} & Aro & $\mathrm{MG} / \mathrm{SP}$ & $\begin{array}{l}\text { Ensino Regular - } \\
\text { Ensino Médio ( } \mathrm{I} \text { o } \\
\text { ano) }\end{array}$ & Obrigatória & Formal (sala de aula) \\
\hline & AII & RN & $\begin{array}{l}\text { Ensino Superior - } \\
\text { Licenciatura em } \\
\text { Física (finalistas) }\end{array}$ & Obrigatória & Formal (sala de aula) \\
\hline $2019 / 36$ & Al2 & $\mathrm{SC}$ & $\begin{array}{l}\text { Ensino Regular - } \\
\text { Ensino Médio ( } 2^{-} \\
\text {ano) }\end{array}$ & Voluntária & Formal (sala de aula) \\
\hline $2020 / 37$ & $\mathrm{~A}_{13}$ & $\mathrm{ES} / \mathrm{PR}$ & $\begin{array}{l}\text { Ensino Superior - } \\
\text { Licenciatura em } \\
\text { Física (discentes } \\
\text { que cursaram ou } \\
\text { estavam cursando } \\
\text { Física Moderna) }\end{array}$ & Voluntária & $\begin{array}{l}\text { Formal (sala de aula } \\
\text { e laboratório de física } \\
\text { computacional da } \\
\text { universidade) }\end{array}$ \\
\hline
\end{tabular}

Fonte: Elaborada pelos autores (202I)

Aproximadamente $69,23 \%$ dos artigos analisados são voltados para o Ensino Médio abrangendo todas as três séries, contando com 9 artigos. Aproximadamente 23,07 \% são voltados para o Ensino Superior, onde a HFC foi aplicada a alunos finalistas, 
iniciantes ou com algum requisito (disciplina), totalizando 3 artigos. Já o artigo Aır foi classificado como "Formação de Professores" por ser aplicado para professores graduados e atuantes no ensino de Física, representando aproximadamente 7,69 \% dos artigos analisados. Também se nota a participação dos envolvidos e o espaço físico destinado para o trabalho. Em grande parte, a participação foi voluntária e ocorreu em sala de aula (algumas também em laboratórios da própria instituição). Sobre a localização geográfica dos autores, constata-se que não houve artigos oriundos da região Norte e Centro-Oeste do Brasil. Podemos também verificar que há autores de estados e regiões diferentes trabalhando em conjunto.

Alguns artigos publicados são resultados de pesquisas de programas de pósgraduação stricto sensu (mestrado e doutorado), dos quais podemos enunciar: Aos (Dissertação - Mestrado em Ensino de Ciências e Matemática - CEFET/RJ); Ao7 (Dissertação - Mestrado em Ciência, Tecnologia e Educação - CEFET/RJ); Aıo (Dissertação - Mestrado em Ensino de Física - USP) e Aız (Tese - Doutorado em Ensino de Ciências de Matemática - UEL). Dos enunciados acima apenas a dissertação em que foi baseado o trabalho Ao7 não foi encontrada nas referências, porém foi citado no corpo do texto que é síntese de um trabalho de mestrado. Referências desta natureza têm papel importante porque trazem informações mais detalhadas acerca dos trabalhos que envolvem a aplicação da HFC em sala de aula, como seus materiais, metodologias, resultados e considerações do autor.

Podemos levar em consideração que os artigos possuem ligação com grupos de pesquisa, entre eles estão: Aor (Grupo Tekné - Contadores de História (da Ciência) Independente); Aos (Grupo de Pesquisa em Educação Científica, História da Ciência e Cultura - CEFET/RJ); Aog (GHCEN - Grupo de História da Ciência e Ensino UEPB); Aro (TeHCo - Teoria e História do Conhecimento - USP) e Ai3 (IFHIECEM - Investigações em Filosofia e História da Ciência, e Educação em Ciências e Matemática - UEL). Com exceção do artigo Aor, o restante dos artigos tem ligação com alguma instituição de ensino superior. Mesmo sendo independente, o grupo Tekné possui vários materiais publicados. Essa ligação com grupos de pesquisa é interessante 
para quem pesquisa sobre HFC porque além dos artigos do CBEF aqui classificados, pode-se consultar os demais trabalhos desenvolvidos por esses grupos e assim ampliar os conhecimentos acerca de História e Filosofia da Ciência.

Abaixo se encontra uma tabela (Tabela 4) na qual cita algumas características das propostas didáticas acerca de Teorias de Aprendizagem, objetivos, materiais e métodos dos artigos de HFC em sala de aula. Os artigos estão citados por indicadores, que se encontram nomeados nas Tabelas 2 e 3:

Tabela 4 - Teorias e Métodos da HFC em Sala de Aula (CBEF 2010 - 2020)

\begin{tabular}{|c|c|c|c|c|c|}
\hline $\begin{array}{c}\text { Ano/ } \\
\text { Volum } \\
\text { e }\end{array}$ & $\begin{array}{l}\text { Indica } \\
\text { dor }\end{array}$ & $\begin{array}{c}\text { Teoria(s) da } \\
\text { Aprendizagem }\end{array}$ & Objetivo(s) & Material(is) & Método(s) \\
\hline $2010 / 27$ & Aor & Não citado & $\begin{array}{l}\text { Incentivar à inovação das } \\
\text { práticas educativas, a } \\
\text { importância da criatividade e da } \\
\text { ousadia no ensino da Física, } \\
\text { como forma de resgatar o } \\
\text { interesse e a credibilidade do } \\
\text { aluno que já não vê na sala de } \\
\text { aula nenhuma correspondência } \\
\text { com o mundo de que faz parte }\end{array}$ & $\begin{array}{c}\text { Peça “A Vida de Galileu”, de } \\
\text { Bertolt Brecht. Livro } \\
\text { paradidático "Galileu e o } \\
\text { Nascimento da Ciência } \\
\text { Moderna" (GUERRA et al.). } \\
\text { Bibliografia complementar } \\
\text { indicada por professores de } \\
\text { História da Arte, História } \\
\text { Geral, Física e Filosofia. } \\
\text { Vídeos “O Império dos } \\
\text { Médicis" (History Channel), } \\
\text { "Os Patronos do } \\
\text { Renascimento" (PBS), } \\
\text { "Galileo's Life" (Bertold } \\
\text { Brecht e dirigido por Joseph } \\
\text { Losey). Repertório musical. }\end{array}$ & $\begin{array}{c}\text { Leitura e adaptação } \\
\text { da peça. Diagnóstico } \\
\text { inicial. Seminários e } \\
\text { pesquisas em grupo } \\
\text { para discussão acerca- } \\
\text { dos temas propostos } \\
\text { na peça. } \\
\text { Apresentação da } \\
\text { peça. }\end{array}$ \\
\hline $2011 / 28$ & Ao2 & Não citado & $\begin{array}{l}\text { Mostrar que o conhecimento e a } \\
\text { manipulação, pelos alunos, de } \\
\text { aparatos experimentais } \\
\text { históricos pode ser um caminho } \\
\text { para trazer às aulas de Física } \\
\text { discussões que possibilitam } \\
\text { diminuir o distanciamento entre } \\
\text { o ensino de Física e a tecnologia. }\end{array}$ & $\begin{array}{c}\text { Livro paradidático "Faraday } \\
\text { e Maxwell: } \\
\text { Eletromagnetismo da } \\
\text { Indução aos Dínamos" } \\
\text { (GUERRA, BRAGA, } \\
\text { REIS). Equipamento } \\
\text { histórico: Máquina } \\
\text { eletrostática de Wimshurt, } \\
\text { réplica da pilha de Volta } \\
\text { (acervo do laboratório da } \\
\text { escola). Lanterna de indução, } \\
\text { celular, rádio portátil } \\
\text { (década de 8o) }\end{array}$ & $\begin{array}{c}\text { Entrevista } \\
\text { semiestruturada } \\
\text { (escolha do tema } \\
\text { “eletromagnetismo } \\
\text { ”). } \\
\text { Desenvolvimento } \\
\text { de atividades } \\
\text { experimentais em } \\
\text { grupo (confeção } \\
\text { de } \\
\text { experimentos que } \\
\text { serviriam de base } \\
\text { para o } \\
\text { experimento } \\
\text { final); discussão } \\
\text { em grupo de textos } \\
\text { narrativos sobre o } \\
\text { desenvolvimento } \\
\text { do } \\
\text { eletromagnetismo }\end{array}$ \\
\hline
\end{tabular}




\begin{tabular}{|c|c|c|c|c|c|}
\hline & & & & & $\begin{array}{c}\text { (discussão } \\
\text { histórica); } \\
\text { questionário } \\
\text { prévio e } \\
\text { construção de um } \\
\text { transmissor de } \\
\text { ondas } \\
\text { eletromagnéticas } \\
\text { rudimentar, } \\
\text { baseado no Arco } \\
\text { de Poulsen } \\
\text { (experimento } \\
\text { histórico). }\end{array}$ \\
\hline $2012 / 29$ & $\mathrm{Ao}_{3}$ & Não citado & $\begin{array}{c}\text { Valorizar aspectos históricos } \\
\text { relacionados ao experimento, } \\
\text { mobilizando os estudantes de } \\
\text { modo a auxiliá-los na construção } \\
\text { de conhecimentos sobre } \\
\text { Astronomia. }\end{array}$ & $\begin{array}{c}\text { Revista ibero-americana de } \\
\text { Humanidades, Ciências e } \\
\text { Educação. São Paulo, } \\
\text { v.7.n.I2.dez. 2021. } \\
\text { ISSN - } 2675 \text { - } 3375\end{array}$ & $\begin{array}{c}\text { Projeto } \\
\text { consolidado em } \\
\text { outros países. } \\
\text { Inscrições no site } \\
\text { do projeto. } \\
\text { Atividades } \\
\text { complementares: } \\
\text { visita ao planetário } \\
\text { local e confecção } \\
\text { de relatório de } \\
\text { atividades } \\
\text { desenvolvidas no } \\
\text { local, tradução de } \\
\text { emails do espanhol } \\
\text { para o português } \\
\text { (recebidos das } \\
\text { escolas parceiras } \\
\text { do projeto), } \\
\text { questionários e } \\
\text { pesquisa na } \\
\text { internet sobre a } \\
\text { cultura dos povos } \\
\text { dos países que } \\
\text { participaram desse } \\
\text { projeto. Atividades } \\
\text { experimentais: uso } \\
\text { de materiais para } \\
\text { cálculo da } \\
\text { inclinação dos } \\
\text { raios solares e } \\
\text { distância entre os } \\
\text { paralelos que } \\
\text { passam da escola } \\
\text { do discente e da } \\
\text { escola parceira, uso } \\
\text { dos softwares da } \\
\text { coluna à esquerda } \\
\text { para determinar o } \\
\text { horário } \\
\text { correspondente ao } \\
\text { meio-dia solar nas } \\
\text { datas combinadas } \\
\text { previamente com } \\
\text { as escolas } \\
\text { parceiras, }\end{array}$ \\
\hline
\end{tabular}




\begin{tabular}{|c|c|c|c|c|c|}
\hline & & & & & $\begin{array}{c}\text { determinar } \\
\text { latitude e } \\
\text { longitude da escola } \\
\text { do discente e } \\
\text { comparar esses } \\
\text { resultados obtidos } \\
\text { experimentalment } \\
\text { e com os dados dos } \\
\text { softwares. } \\
\text { Avaliação escrita. }\end{array}$ \\
\hline \multirow{2}{*}{$2015 / 32$} & Ao4 & Não citado & $\begin{array}{l}\text { Discutir sobre a origem do } \\
\text { Universo e, principalmente, } \\
\text { despertar no grupo uma postura } \\
\text { reflexiva sobre a construção da } \\
\text { Ciência. }\end{array}$ & $\begin{array}{c}\text { Texto de apoio "Do Big } \\
\text { Bang ao Universo" e "O que } \\
\text { é Cosmologia? A Revolução } \\
\text { do Pensamento } \\
\text { Cosmológico" } \\
\text { (NOVELLO). }\end{array}$ & $\begin{array}{l}\text { Questionário pré- } \\
\text { teste. Leitura do } \\
\text { texto de apoio e } \\
\text { pesquisa de } \\
\text { materiais na } \\
\text { internet. Discussão e } \\
\text { exposição de } \\
\text { cartazes em grupo a } \\
\text { fim de argumentar } \\
\text { sobre os modelos } \\
\text { cosmológicos. } \\
\text { Questionário pós- } \\
\text { teste. } \\
\end{array}$ \\
\hline & Aos & Não citado & $\begin{array}{l}\text { Construir subsídios para } \\
\text { informar que elementos do tema } \\
\text { espectroscopia desenvolvidos em } \\
\text { aulas de Física, numa abordagem } \\
\text { histórico-filosófica, } \\
\text { complementam o estudo de } \\
\text { modelo atômico realizado nas } \\
\text { aulas de Química do Ensino } \\
\text { Médio. }\end{array}$ & $\begin{array}{l}\text { Texto produzido baseado em } \\
\text { fontes primárias e } \\
\text { secundárias de historiadores } \\
\text { reconhecidos pela } \\
\text { comunidade de História da } \\
\text { Ciência contendo II } \\
\text { capítulos. Slides com mais } \\
\text { imagens que textos. } \\
\text { Gravador de vídeo. Kit } \\
\text { experimental de baixo custo, } \\
\text { kit experimental próprio } \\
\text { para laboratório e manual de } \\
\text { instruções. Vídeos. }\end{array}$ & $\begin{array}{l}\text { Produção do texto } \\
\text { após as reuniões } \\
\text { (exceção dos dois } \\
\text { primeiros capítulos). } \\
\text { Discussão acerca dos } \\
\text { textos previamente } \\
\text { enviados aos alunos. } \\
\text { Apresentação de } \\
\text { slides. Apresentação } \\
\text { oral do questionário. } \\
\text { Atividades } \\
\text { experimentais. }\end{array}$ \\
\hline
\end{tabular}




\begin{tabular}{|c|c|c|c|c|c|}
\hline \multirow[t]{2}{*}{$2016 / 33$} & Ao6 & Não citado & $\begin{array}{l}\text { Avaliar uma proposta com } \\
\text { abordagem de história da ciência } \\
\text { por meio de um minicurso à } \\
\text { distância. Sugerir e motivar o } \\
\text { estudo de casos históricos da } \\
\text { ciência no Brasil, colocando } \\
\text { assim, os professores em contato } \\
\text { com experimentos e contextos } \\
\text { nacionais ao invés de focar } \\
\text { apenas a ciência europeia e/ou } \\
\text { norte-americana. }\end{array}$ & $\begin{array}{l}\text { Textos anexados no } \\
\text { ambiente virtual: "Minas } \\
\text { Gerais e a História do } \\
\text { Ferromagnetismo" } \\
\text { (PIMENTEL; } \\
\text { YAMAMURA), “Theodoro } \\
\text { Ramos e os Primórdios da } \\
\text { Física Moderna no Brasil" } \\
\text { (STUDART et al.), "John } \\
\text { Archibald Wheeler e a Física } \\
\text { Brasileira" (JUNIOR; } \\
\text { BASSALO), "A Terra Gira! } \\
\text { I85I: A Primeira Experiência } \\
\text { com o Pêndulo de Foucault } \\
\text { no Brasil" (MOREIRA) e } \\
\text { "Henrique Morize, Os } \\
\text { Raios-X e os Raios } \\
\text { Catódicos" (MOREIRA). } \\
\text { Episódios históricos: } \\
\text { episódios históricos no } \\
\text { ensino de ciências, oscilações } \\
\text { e mediçóes no Brasil } \\
\text { Colonial, o desenvolvimento } \\
\text { das máquinas térmicas no } \\
\text { século XIX, o padre Ignácio } \\
\text { Monteiro: as máquinas } \\
\text { simples e as controvérsias do } \\
\text { ensino português do século } \\
\text { XVIII. }\end{array}$ & $\begin{array}{c}\text { Construção de uma } \\
\text { sala virtual (Moodle), } \\
\text { do qual houve } \\
\text { encontros } \\
\text { presenciais e aulas à } \\
\text { distância. Ambiente } \\
\text { Virtual: participação } \\
\text { em fórum, interação } \\
\text { com a simulação } \\
\text { computacional, } \\
\text { envio de arquivo } \\
\text { único, acesso aos } \\
\text { vídeos disponíveis, } \\
\text { questionários. } \\
\text { Análise Textual } \\
\text { Discursiva: } \\
\text { construção de } \\
\text { metatextos (texto } \\
\text { descritivo e } \\
\text { interpretativo) } \\
\text { através de uma } \\
\text { sequência didática e } \\
\text { elaboração de uma } \\
\text { sequência didática. }\end{array}$ \\
\hline & $\mathrm{Ao} 7$ & Não citado & $\begin{array}{c}\text { Discutir a importância de } \\
\text { abordar histórica e } \\
\text { filosoficamente os conceitos de } \\
\text { espaço e tempo na educação } \\
\text { básica e apresentar os relatos de } \\
\text { uma experiência realizada em } \\
\text { sala de aula. }\end{array}$ & $\begin{array}{c}\text { Vídeo “Origem da } \\
\text { Cinemática" - disponível } \\
\text { em: } \\
\text { 〈http://youtu.be/nrCZvQD } \\
\text { sPAk>. Animação "A Vida } \\
\text { de Galileu". } \\
\text { Textos (desenvolvidos pelo } \\
\text { próprio professor, com base } \\
\text { em leituras prévias, } \\
\text { apresentadas no marco } \\
\text { histórico desse trabalho). } \\
\text { Vídeo "Quando o } \\
\text { conhecimento venceu o } \\
\text { medo" (3o episódio - } \\
\text { Cosmos: Uma Odisseia no } \\
\text { Espaço-Tempo - Neil De } \\
\text { Grasse Tyson). Vídeo } \\
\text { "Balde de Rotação" - } \\
\text { disponível em: } \\
\text { 〈http://youtu.be/BzsWBED } \\
\text { ALok> e } \\
\text { 〈http://youtu.be/Toy4ToW } \\
\text { MS9U〉 }\end{array}$ & $\begin{array}{l}\text { Atividade de } \\
\text { sondagem } \\
\text { (questionário pré- } \\
\text { teste); Leitura de } \\
\text { textos, produção } \\
\text { textual; Aulas } \\
\text { expositivas; } \\
\text { Exibição de vídeos } \\
\text { e simulações; } \\
\text { Indicação de vídeo } \\
\text { aulas; Produção de } \\
\text { obras pictóricas, } \\
\text { charges e histórias } \\
\text { em quadrinho } \\
\text { (atividade final). }\end{array}$ \\
\hline
\end{tabular}




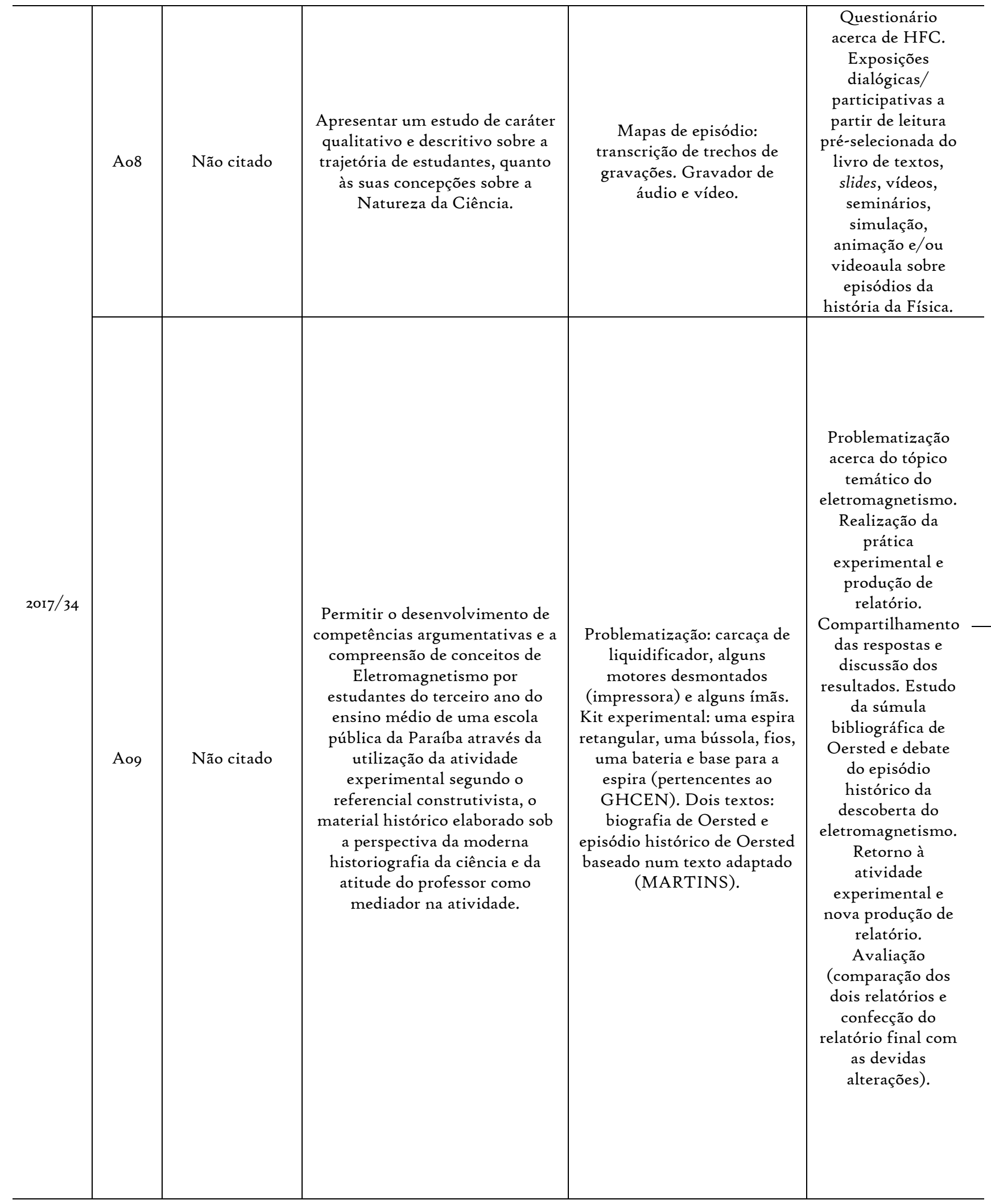




\begin{tabular}{|c|c|c|c|c|c|}
\hline \multirow{2}{*}{$2018 / 35$} & Aro & Não citado & $\begin{array}{l}\text { Analisar argumentos } \\
\text { envolvendo a oposição entre } \\
\text { Einstein e Friedmann e as } \\
\text { concepções dos alunos sobre o } \\
\text { papel dos erros na ciência. }\end{array}$ & $\begin{array}{c}\text { Textos originais de Einstein } \\
\text { e Friedmann acerca do } \\
\text { episódio (traduzidos). } \\
\text { Material do jogo: fichas } \\
\text { impressas em cartões } \\
\text { plástico que contém fotos, } \\
\text { desenhos e textos sobre } \\
\text { acontecimentos históricos. } \\
\text { Disponível em: } \\
\text { 〈http://bityli.com/NmnPI〉. } \\
\text { Fontes primárias e } \\
\text { secundárias sobre a história } \\
\text { da ciência na primeira } \\
\text { metade do século XX } \\
\text { (BAGDONAS - Dissertação } \\
\text { de Mestrado). }\end{array}$ & $\begin{array}{l}\text { Adaptação de um } \\
\text { episódio histórico } \\
\text { para o contexto do } \\
\text { ensino de Física do } \\
\text { ensino médio } \\
\text { através da criação } \\
\text { de um jogo } \\
\text { didático. Estudo de } \\
\text { fontes primárias e } \\
\text { secundárias. } \\
\text { Sequência didática: } \\
\text { investigação, } \\
\text { organização e } \\
\text { aplicação. } \\
\text { Questões } \\
\text { respondidas de } \\
\text { forma oral, escrita } \\
\text { e no blog da } \\
\text { disciplina e } \\
\text { anotações pelo } \\
\text { professor da } \\
\text { disciplina e pelo } \\
\text { primeiro autor do } \\
\text { artigo. Debates } \\
\text { sobre as questões } \\
\text { controversas da } \\
\text { natureza da ciência } \\
\text { (política, economia } \\
\text { e religião). } \\
\end{array}$ \\
\hline & AII & Não citado & $\begin{array}{c}\text { Promover a reflexão crítica sobre } \\
\text { objetos virtuais de aprendizagem } \\
\text { com conteúdo histórico, por } \\
\text { meio de um processo de } \\
\text { desenvolvimento de } \\
\text { modificações em tais recursos de } \\
\text { modo a adequá-los para uso } \\
\text { didático. }\end{array}$ & $\begin{array}{l}\text { Recortes de livros didáticos } \\
\text { para o ensino médio } \\
\text { (HIDALGO). Recortes de } \\
\text { editais do PNLD e da } \\
\text { legislação educacional que } \\
\text { tratam de História da } \\
\text { Ciência. Texto histórico: } \\
\text { tradução de uma carta de } \\
\text { Torricelli para Michelangelo } \\
\text { na qual descreve suas } \\
\text { pesquisas (MAGIE). Artigo } \\
\text { acadêmico sobre a inserção } \\
\text { didática da referida temática } \\
\text { histórica (FONSECA). } \\
\text { Animações digitais com } \\
\text { conteúdo histórico, como } \\
\text { “The History of Barometer”, } \\
\text { produzido por Stephen } \\
\text { Whitlle. Simulação via } \\
\text { Wolfram acerca dos trabalhos } \\
\text { de Torricelli e Pascal. }\end{array}$ & $\begin{array}{c}\text { Fundamentação } \\
\text { para a inserção } \\
\text { didática da HFC; } \\
\text { Análise individual } \\
\text { dos objetos } \\
\text { virtuais pelos } \\
\text { licenciandos; } \\
\text { Discussão coletiva } \\
\text { da compilação de } \\
\text { comentários } \\
\text { individuais } \\
\text { (síntese da turma); } \\
\text { Atividade de } \\
\text { reelaboração do } \\
\text { roteiro da } \\
\text { animação digital } \\
\text { pelos grupos. }\end{array}$ \\
\hline
\end{tabular}




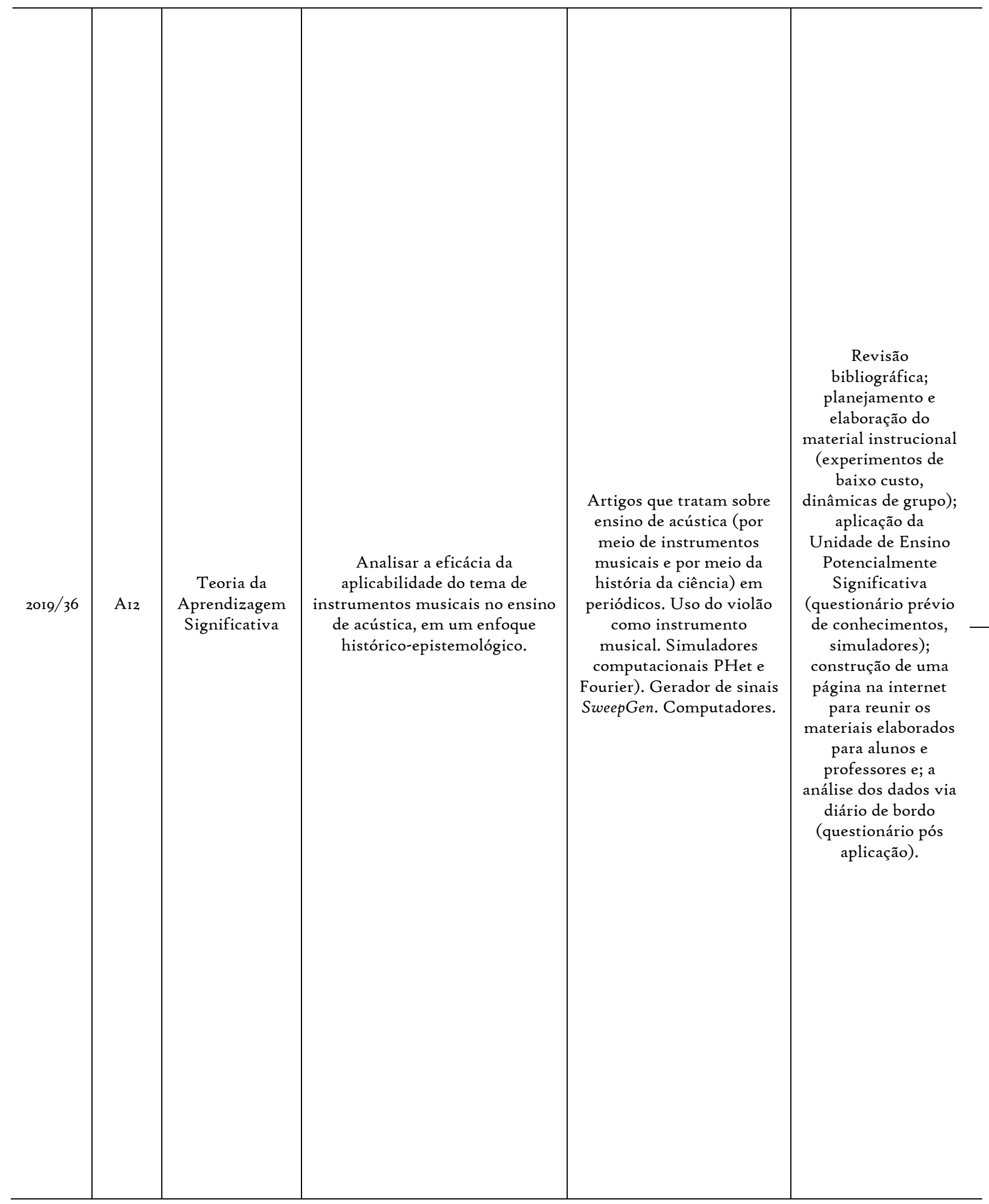




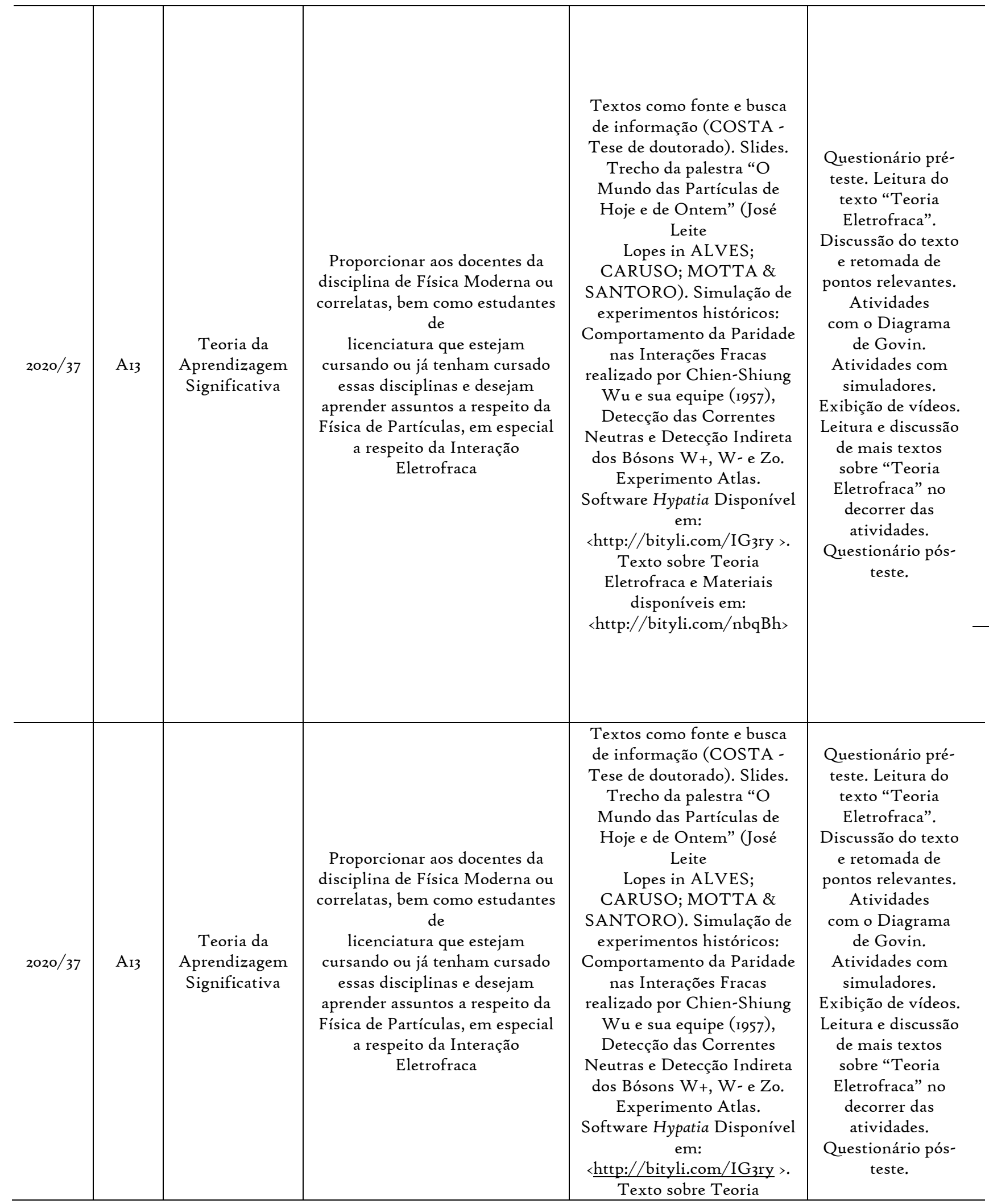




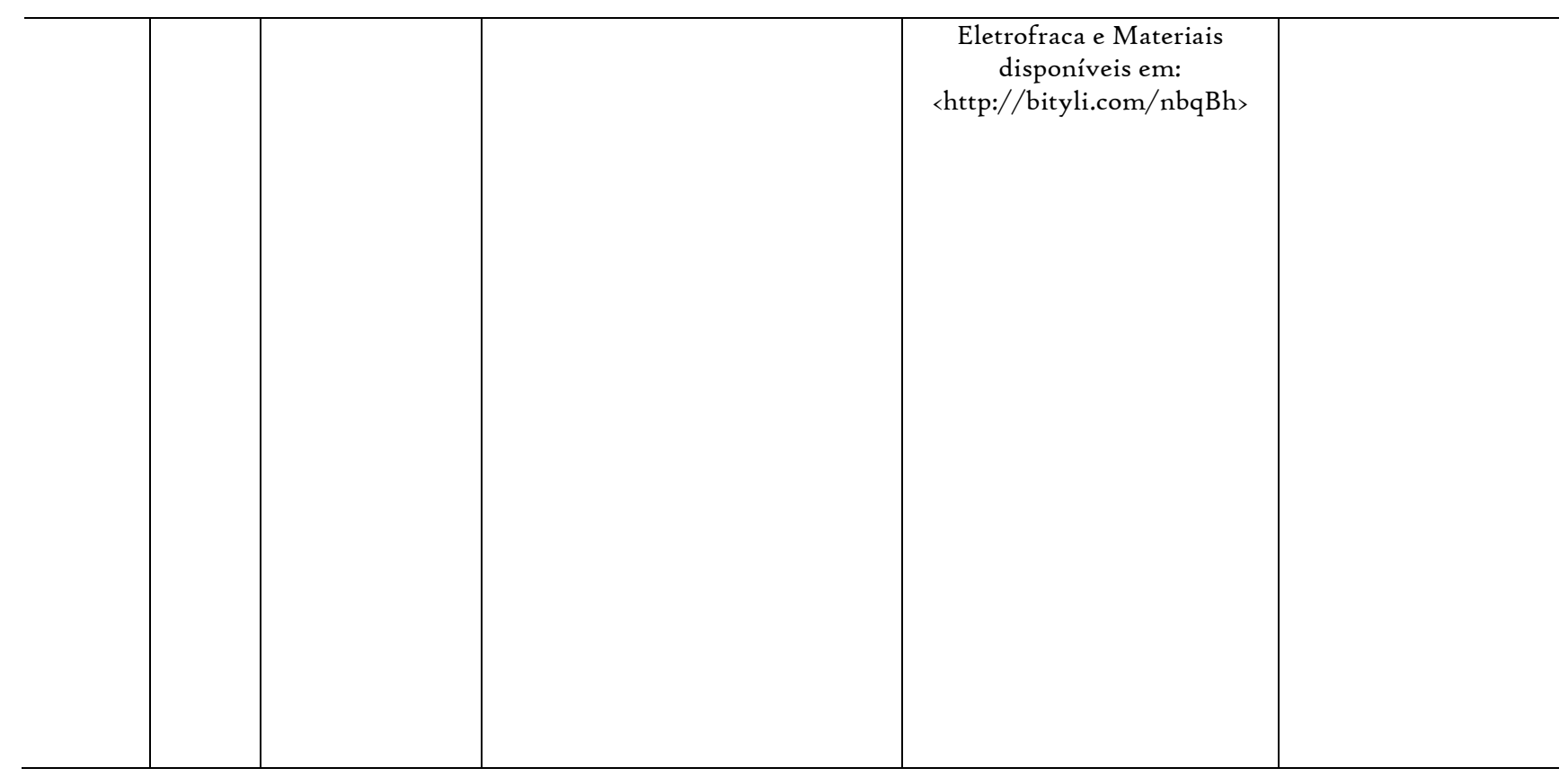

Fonte: Elaborada pelos autores (2021)

Dos 13 artigos analisados, apenas 2 citaram Teorias de Aprendizagem. A Teoria da Aprendizagem Significativa ( $\mathrm{A}_{3}$ e $\mathrm{A}_{14}$ ) foi citada nos artigos dos dois últimos anos (2019 e 2020). Mesmo não sendo citadas teorias de aprendizagem nos demais artigos, foi notada a citação dos Parâmetros Curriculares Nacionais (PCN's) que cita o enfoque da HFC no ensino de Física.

O objetivo geral comum nos 13 artigos analisados visa a reflexão, a argumentação, a compreensão e a crítica do público envolvido acerca das temáticas apresentadas em cada trabalho analisado. Esses objetivos mostram uma ideia clara sobre a contribuição da abordagem de HFC em sala de aula, pois a revela como um diferencial no ensino de Física, que busca um enfoque de ensino mais humanizado e voltado para como a produção científica vem sendo realizada no decorrer do tempo (com questões políticas, econômicas, religiosas, filosóficas) e não descartando o método tradicional de ensino que está estagnado e sim o auxiliando e combinando com outras metodologias no processo de ensino-aprendizagem de Física. 
Levando em consideração os materiais utilizados, notamos a presença de textos históricos (originais) em alguns dos artigos analisados. Nos artigos Aro e Arr utilizamse traduções dos mesmos. Reforçando o que Montenegro (2005) apresenta sobre essa leitura poder aproximar os estudantes dos cientistas fazendo com que estes percebam a ciência como um processo inacabado, ou seja, pois há sempre a possibilidade de uma análise mais recente do mesmo objeto sob uma nova e ainda inexplorada perspectiva.

Em relação aos métodos utilizados nos artigos destacamos que nenhum foi realizado individualmente, sempre em equipe onde houve discussões acerca do material de natureza teórica (slides e vídeos) e dos resultados dos experimentos realizados (experimentos históricos e simulações computacionais). Muitos artigos aplicaram prétestes (sondagem) e pós-testes em sua sequência didática. Cada método segue uma sequência didática distinta, porém nunca individualizando o ensino e priorizando o ensino de forma coletiva. Notamos o uso de metodologias de TICs, experimentação e outros gêneros textuais acerca dos conteúdos de Física em conjunto com a HFC, fortalecendo a ideia de que a união de metodologias seja eficaz no processo de ensinoaprendizagem de Física.

Sobre alguns resultados (segundo os autores) dessas abordagens analisadas, selecionamos dois (02) que se mostraram positivos, dois ( 02 ) negativos e dois ( 02 ) indiferentes:

Positivos: Dos 13 artigos analisados, II demonstraram resultados relativamente positivos, aqui destacamos 2 deles: O primeiro é o artigo Aor, onde os autores avaliaram que os alunos compreenderam os conceitos trabalhados, assim como passaram a entender alguns aspectos da produção científica e como consequência, desenvolveram-se certas habilidades, tais como: oralidade, leitura e interpretação, desinibição, tolerância e trabalho em equipe. Já o segundo artigo que merece destaque com resultados positivos é o artigo $\mathrm{A}_{13}$, onde a abordagem contribuiu para que os alunos enriquecessem os subsunçores já existentes e promoveu um aumento de vocabulário científico e recursividade, utilizando uma linguagem condizente com os assuntos estudados. Segundo os alunos, alguns pontos positivos são: as simulações permitem que se aprenda 
mais em menos tempo; desmistificação de cientistas e da Ciência; simulações e textos originais para o ensino de Física; apresentar os experimentos históricos por meio das simulações.

Negativos: Não foram encontrados resultados considerados negativos nos 13 artigos analisados. Isso não indica o sucesso total da HFC em sala de aula, mas que em sua totalidade os resultados positivos foram superiores aos negativos e esses foram desconsiderados ao final.

Indiferentes: Para fins de resultados indiferentes temos o artigo Ao6, em que se aborda um conteúdo interessante (experimentos realizados no Brasil) e numa modalidade que está ganhando espaço na educação (ensino à distância), porém apresenta os resultados de um dos participantes do projeto aplicado e foi aqui considerado como indiferente. Consideramos também o artigo Ao8, pois o mesmo trata de uma investigação pedagógica de observação e os autores extraem dados das aulas de uma disciplina de um curso de nível superior e não há uma análise de uma sequência didática aplicada pelos autores porque não é o foco do trabalho.

\section{CONSIDERAÇÕES FINAIS}

O trabalho nos revelou que há grande carência de artigos com intervenções didáticas em sala de aula do ensino de Física por meio da abordagem histórico-filosófica no Caderno Brasileiro de Ensino de Física (CBEF) entre 2010 e 2020. É sabido que muitas pesquisas oriundas da pós-graduação ainda não são apresentadas em artigos. Nos trabalhos analisados foi possível perceber grande aceitação dos alunos, quanto à metodologia utilizada, pois passaram a entender a Física para muito além das equações e fórmulas. Uma mudança curricular deve ser discutida não somente a nível escolar, mas também em cursos de formação de professores, visto que é imprescindível o domínio do conteúdo para que a abordagem atinja os objetivos esperados, já que há menção na Base Nacional Comum Curricular (BNCC).

Em relação ao material didático utilizado nos trabalhos, os autores destacam a importância na análise do conteúdo, pois vários livros didáticos reforçam a ideia de 
construção linear e imutável da Ciência, o que contraria a finalidade das propostas, cabendo ao docente especificar o material apropriado para utilização ou conseguir neutralizar possibilidades das visões distorcidas da Ciência.

Por fim, constatamos que as pesquisas em Ensino de Física por meio da abordagem histórico-filosófica estão evoluindo aos poucos, pois passaram a ser aplicações e apresentando resultados em sala de aula, ressaltando que por meio dessa abordagem os discentes desenvolveram uma visão crítica e ampla sobre questões da Natureza da Ciência e a construção do conhecimento científico. Porém, como pesquisadores, devemos analisar os resultados a fim de melhorar essa abordagem em sala de aula, unindo com outras abordagens para melhorar o processo de ensinoaprendizagem de Física.

\section{REFERÊNCIAS}

BAGDONAS, A.; ZANETIC, J.; GURGEL, I. O maior erro de Einstein? Debatendo o papel dos erros na ciência através de um jogo didático sobre cosmologia. Caderno Brasileiro de Ensino de Física. Florianópolis, v. 35, n. I, p. 97-117, 2018.

BASSALO, J. M. F. A importância do estudo da história da ciência. Revista da Sociedade Brasileira de História da Ciência, n. 8, p. 57-66, 1992.

BASTOS, F. História da ciência e pesquisa em ensino de ciências. In: NARDI, R. (org). Questões Atuais no Ensino de Ciências. São Paulo: Escrituras Editora, 1998, p.4352.

BENNETT, J. et al. Systematic reviews of research in science education: rigour or rigidity? International Journal of Science Education, London, v. 27, n. 4, p. 387- 406. mar. 2005.

BRAGA, M. A. B.; MEDINA, M. N. O teatro como ferramenta de aprendizagem da física e de problematização da natureza da ciência. Caderno Brasileiro de Ensino de Física, Florianópolis, v. 27, n. 2, p. 313-333, 2010.

BRASIL. Base Nacional Comum Curricular: Ensino Médio. Brasília: Ministério da Educação, 2018. 
BRASIL. Parâmetros Curriculares Nacionais: Ensino Médio. ra. ed. Brasília: Ministério da Educação, 1999 .

CBEF. Caderno Brasileiro de Ensino de Física - Sobre a Revista. Disponível em: < http://periodicos.ufsc.br/index.php/fisica > Acesso em: 26 fev. 202I.

CHICÓRA, T.; CAMARGO, S.; TOPPEL, A. História e filosofia da ciência no ensino de física moderna. XII EDUCERE - Congresso Nacional de Educação, 2015. Disponível em: 〈http://educere.bruc.com.br/arquivo/pdf2015/2248I_9958.pdf 〉 Acesso em: 30 mar. 2021.

COSTA, M.; LOURDES, I. Abordagem histórico-didática para o ensino da teoria eletrofraca utilizando simulações computacionais de experimentos históricos. Caderno Brasileiro de Ensino de Física. Florianópolis, v. 37, n. I, p. 242-262, 2020.

DIOS, J. G.; SANTAMARÍA, A. B. Revisión sistemática y metanálisis (I): conceptos básicos. Evidencias em Pediatría. v. 3, n. 4, p. 107, dec. 2007.

FIGUEIREDO, N. Da importância dos artigos de revisão da literatura. Revista Brasileira de Biblioteconomia e Documentação, São Paulo, v. 23, n. I/4, p. 131-135, jan./dez. 1990.

GUIMARÃES, R. R.; MASSONI, N. T. Relato crítico de uma experiência didática acerca de uma temática científica aplicada na educação básica: algumas reflexões epistemológicas e a defesa de um ensino de ciências fundamentado na argumentação dialógica. Caderno Brasileiro de Ensino de Física. Florianópolis, v. 37, n. 2, p. 695-717, 2020.

GUTTMANN, G. A. M.; BRAGA, M. A origem do universo como tema para discutir a natureza da ciência no ensino médio. Caderno Brasileiro de Ensino de Física, Florianópolis, v. 32, n. 2, p. 442-46o, 2015.

HIDALGO, J. M.; SCHIVANI, M.; MARTINS, M. S. História e filosofia da ciência na formação docente: trabalhando com animações digitais. Caderno Brasileiro de Ensino de Física. Florianópolis, v. 35, n. 3, p. 805-850, 2018.

JUNIOR, E. R. et al. Um estudo de caso histórico sobre o experimento de Foucault no Brasil, elaborado por uma professora do ensino médio na formação continuada a distância. Caderno Brasileiro de Ensino de Física. Florianópolis, v. 33, n. I, p. 162-193, 2016. 
LAKATOS, I. História da ciência e suas reconstruções racionais. Lisboa: Edições 70, 1998.

LIMA, D. O.; DAMASIO, F. O violão no ensino de acústica: uma proposta com enfoque histórico-epistemológico em uma unidade de ensino potencialmente significativa. Caderno Brasileiro de Ensino de Física. Florianópolis, v. 36, n. 3, p. 818840, 2019.

MARTINS, A. F. P. História e filosofia da ciência no ensino: há muitas pedras nesse caminho... Caderno Brasileiro de Ensino de Física, Florianópolis, v. 24, n. I, p. II2-I3I, 2007 .

MARTINS, R. A. Introdução: a história das ciências e seus usos na educação. In: SILVA, C. C. (org). Estudos de história e filosofia das ciências: subsídios para aplicação no ensino. São Paulo: Livraria da Física, 2006, p. xxi-xxxiv.

MATTHEWS, M. R. História, filosofia e ensino de ciências: a tendência atual de reaproximação. Caderno Catarinense de Ensino de Física, Florianópolis, v. 12, n. 3, p. 164 - 214, dez. 1995.

MONTENEGRO, A. G. P. M. A leitura de textos originais de Faraday por alunos do ensino fundamental e médio. 2005. 98 p. Dissertação (Mestrado). Faculdade de Educação, Universidade Estadual de Campinas. Campinas, 2005.

NEVES, M. D. A história da ciência no ensino de física. Ciência \& Educação, v.5, n.I, p.73-8I, 1998.

PEDDUZZI, L. O. Q. Sobre a utilização didática da história da ciência. In: PIETROCOLA, M. Ensino de física: conteúdo, metodologia e epistemologia numa concepção integradora. Florianópolis: Editora da UFSC. Cap. 7, p. 151-170, 2001.

PENA, F. L. A.; TEIXEIRA, E. S. Concepções sobre a natureza da ciência: a trajetória dos estudantes de uma disciplina sobre evolução dos conceitos da física. Caderno Brasileiro de Ensino de Física. Florianópolis, v. 34, n. I, p.152-175, 2017.

PENITENTE, L. A. A.; CASTRO, R. M. A História e filosofia da ciência: contribuições para o ensino de ciências e para a formação de professores. Revista Eletrônica Pesquiseduca, v. 2, n. 4, p. 23I-244, $201 \mathrm{I}$. 
PEREIRA, R. C.; MACÊDO, H. R. A.; RODRIGUES, I. L. A inserção da história e filosofia da ciência no ensino de ciências: uma visão geral a partir da análise de artigos disponíveis no portal periódico da Capes. Conexões Ciência e Tecnologia. Fortaleza/CE, v.13, n. 4, p. 54-62, dez. 2019.

PESSOA JUNIOR, O. Quando a abordagem histórica deve ser usada no ensino de ciências? Ciência \& Ensino, n. I, p. 4-6, 1996.

PINTO, J. A. F.; SILVA, A. P. B.; FERREIRA, E. J. B. Laboratório desafiador e história da ciência: um relato de experiência com o experimento de Oersted. Caderno Brasileiro de Ensino de Física. Florianópolis, v. 34, n. I, p. 176-196, 2017.

REIS, U. V.; REIS, J. C. Os conceitos de espaço e de tempo como protagonistas no ensino de física: um relato de uma sequência didática com abordagem históricofilosófica. Caderno Brasileiro de Ensino de Física. Florianópolis, v. 33, n. 3, p. 744-778, 2016.

RINALDI, E.; GUERRA, A. história da ciência e o uso da instrumentação: construção de um transmissor de voz como estratégia de ensino. Caderno Brasileiro de Ensino de Física, Florianópolis, v. 28, n. 3, p.653-675, 2011.

ROBILOTTA, M. R. O cinza, obranco e o preto - da relevância da história da ciência no ensino da física. Caderno Catarinense de Ensino de Física, v. 5, n. especial, p. 7-22, 1988.

ROCHA, T. U. As contribuições da história e filosofia da ciência para o ensino de física quântica na educação básica. 2013.319 p. Dissertação (Mestrado). Setor de Ciências Exatas. Universidade Federal do Paraná. Curitiba, 2013.

SAITO, F. História da ciência e ensino: em busca de diálogo entre historiadores e educadores. História da Ciência e Ensino: construindo interfaces. São Paulo, vol. I, p. I6, 2010.

SANTOS, A. J. J.; VOELZKE, M. R.; ARAÚJO, M. S. T. O projeto Erastótenes: a reprodução de um experimento histórico como recurso para a inserção de conceitos da astronomia no ensino médio. Caderno Brasileiro de Ensino de Física, v. 29, n. 3, p. I137II74, 2012.

SAUERWEIN, I. P. S.; DELIZOICOV, D. Formação continuada de professores de física do ensino médio: concepções de formadores. Caderno Brasileiro de Ensino de Física, Florianópolis, v. 25, n. 3, p. 439-477, 2008. 
SILVA, A. C.; CYRINEU, A. A. História da ciência no ensino básico de física: quais tópicos fazem parte dessa história? Revista Internacional de Formação de Professores, Itapetininga, v. 3, p. 35-44, 2018.

SILVA, B. V. C. Um debate na escola: a história e a filosofia da ciência em foco. Física na Escola, v. II, n. 2, p. 12-15, 2010.

SILVA, H. R. A.; MORAES, A. G. O estudo da espectroscopia no ensino médio através uma abordagem histórico-filosófica: possibilidade de interseção entre as disciplinas de química e física. Caderno Brasileiro de Ensino de Física. Florianópolis, v. 32, n. 2, p. 378-406, 2015.

TRINDADE, L. S. P. et al. História da ciência e ensino: alguns desafios. In: BELTRAN, M. H. R.; SAITO, F.; TRINDADE, L. S. P. (orgs). História da ciência: tópicos atuais. São Paulo: Editora Livraria da Física, 2010, p.I19-132. 